\title{
Perforated diverticulitis of the appendix: ultrasonographic diagnosis
}

\author{
Diverticulite perfurada do apêndice cecal: diagnóstico ultrassonográfico
}

\author{
Rafael Burgomeister Lourenço ${ }^{1}$, Marco da Cunha Pinho ${ }^{1}$, Vladimir Schraibman ${ }^{1}$, Antônio Luiz de Vasconcellos \\ Macedo $^{1}$, Miguel José Francisco Neto ${ }^{1}$, Marcelo Buarque de Gusmão Funari ${ }^{1}$
}

\begin{abstract}
Appendiceal diverticulitis is an uncommon condition, mimicking appendicitis, but with greater risk of perforation and complications. Preoperative diagnosis is rare, but can be achieved by ultrasonography as identification of the diverticulum and classical signs of appendicitis. We report a case of ultrasonographic diagnosis of a perforated appendiceal diverticulitis in an adult male and discuss this condition.
\end{abstract}

Keywords: Appendix; Diverticulum; Diverticulitis/ultrasonography; Diverticulitis/diagnosis; Case reports

\section{RESUMO}

A diverticulite do apêndice é uma patologia incomum, eventualmente confundida com a apendicite cecal, tendo, porém, maior risco de perfuração e de outras complicações. Seu diagnóstico pré-cirúrgico é raramente realizado, mas pode ser obtido pela ultrassonografia com a demonstração de um divertículo associado a sinais clássicos de apendicite. Relatamos o caso de um homem adulto em que foi possível o diagnóstico ultrassonográfico de diverticulite do apêndice cecal e revisamos os principais aspectos relacionados a essa condição.

Descritores: Apêndice; Divertículo; Diverticulite/ultrassonografia; Diverticulite/diagnóstico; Relatos de casos

\section{INTRODUCTION}

Appendiceal diverticulitis is an uncommon, but not exceedingly rare condition, usually overlooked by the diagnostic imaging methods. The clinical picture mimics appendicitis, but it has some differences with implications in treatment and prognosis. We report a case of ultrasonographic diagnosis of a perforated appendiceal diverticulitis in an adult male and discuss this condition.

\section{CASE REPORT}

A 61-year-old male, previously hypertensive, sought medical care with a history of 36 hours of low fever $\left(38.4^{\circ} \mathrm{C}\right)$, constipation and tenderness in the lower right abdominal quadrant. Laboratory studies demonstrated leukocytosis (white blood cell count of 15700 cells/ $\mu$ l), without other abnormal results.

He was referred to the diagnostic imaging center, where ultrasonography was performed in an ATL HDI 5000 ultrasound scanner (Philips Medical Systems - Erlangen) with a high resolution linear-array multifrequency 7-12 MHz transducer.

The ultrasonography showed a diffusely thickened and non-compressible appendix, with two saccular outpouchings $(0.4$ and $0.5 \mathrm{~cm})$ projecting beneath the muscular layer (Figure 1). A small perforation and fluid collection was identified adjacent to the larger diverticulum. A regional inflammatory reaction was identified by a "ground glass" hiperecogenicity of the fat and reactive thickening of the terminal illeum and cecum (Figure 2).

The patient underwent surgery. Surgical finding was a profuse inflammatory reaction in the distal ileum, appendix, cecum and ascending colon, associated with a small abscess. As malignancy could not be excluded from the macroscopic appearance, a right hemicolectomy was performed. The postoperative period was uneventful and the patient returned to his activities a few days

Study carried out at Hospital Israelita Albert Einstein - HIAE, São Paulo (SP), Brazil.

1 Hospital Israelita Albert Einstein - HIAE, São Paulo (SP), Brazil.

Corresponding author: Rafael Burgomeister Lourenço - Serviço de Medicina Diagnóstica de Preventiva - Departamento de Imagem - Hospital Albert Einstein - Rua Albert Einstein, 627/701, $4^{\circ}$ andar Morumbi - CEP 05651-901 - São Paulo (SP), Brasil - Tel.: 11 3061-3009 - e-mail: rafaburgo@hotmail.com

Received on Aug 21, 2008 - Accepted on Dec 20, 2010

The authors declare there is no conflict of interest. 


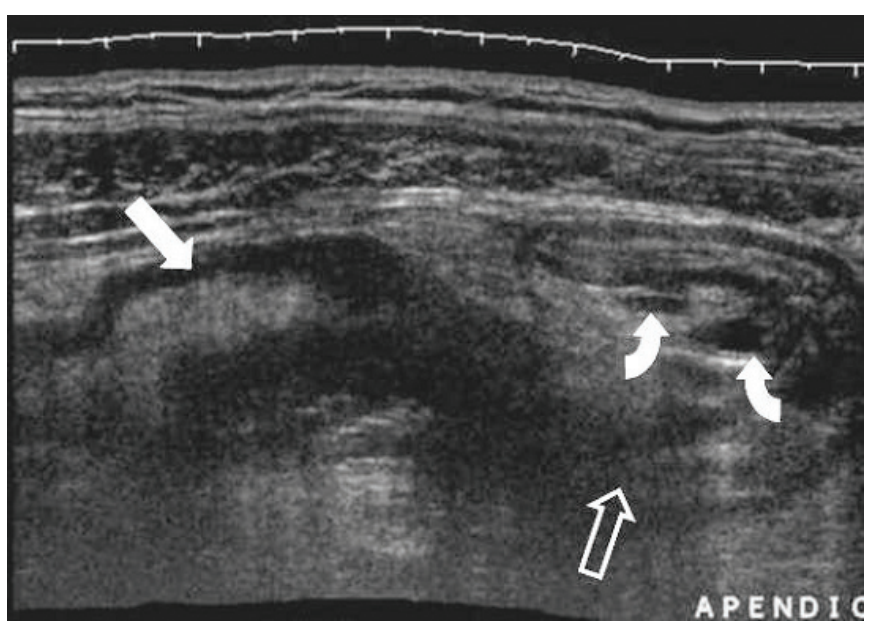

Figure 1. Right parasagittal panoramic image. Thickening of the cecum wall (bold arrow) with a rigid thickened appendix, curved anteriorly (open arrow $=$ base). Two small outpouchings can be seen at the mesoappendiceal margin (curved arrows). Note difuse "ground glass" hyperechogenicity of the adjacent fat.

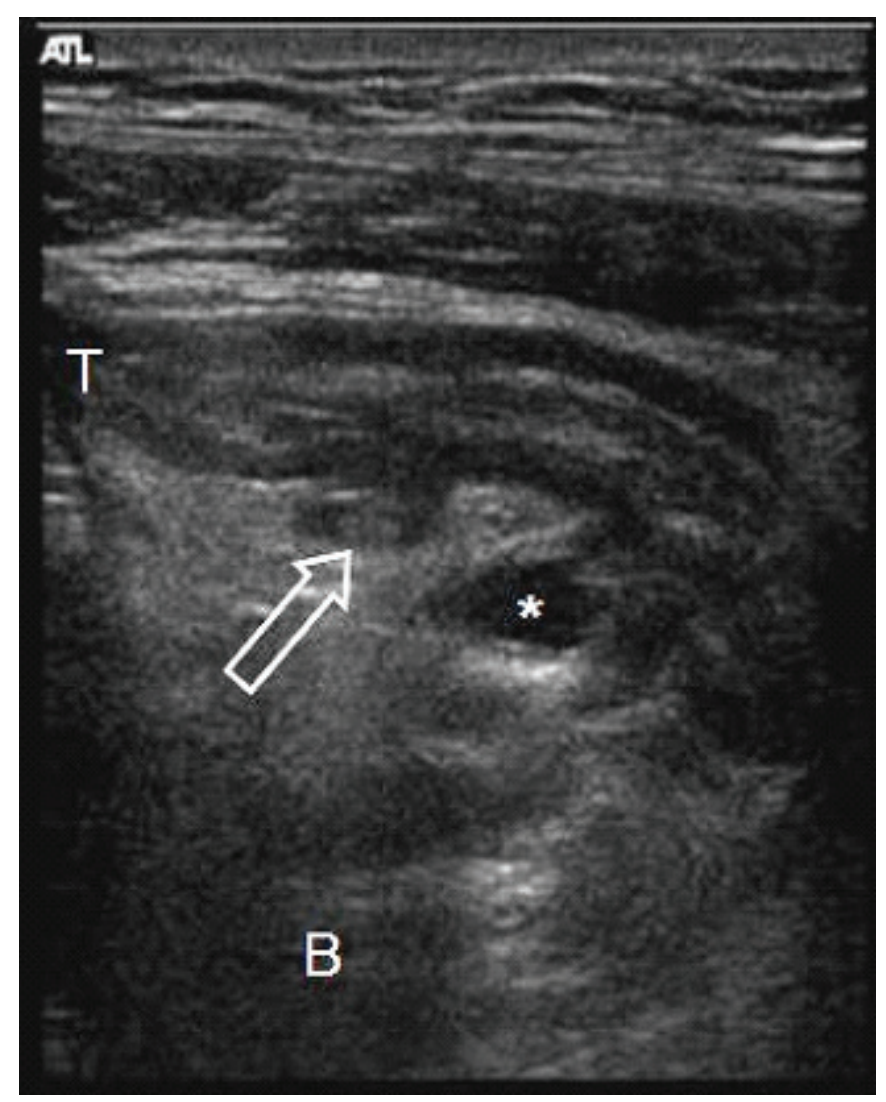

Figure 2. Localized parasagittal image. Small fluid collection $\left.{ }^{*}\right)$ adjacent the perforated diverticulum. Another non-perforated diverticulum (open arrow) was identified near the tip (T). B: base.

after the procedure. Pathologic examination showed multiple acquired diverticula in the colon, cecum and appendix. One of the appendiceal diverticulum showed suppurative diverticulitis, with perforation and reactive appendicitis. There were also intense reactive inflammatory signs in the colon and terminal ileum, without evidence of malignancy.

\section{DISCUSSION}

Diverticulitis of the appendix is a rare condition that results from inflammation of an appendiceal diverticulum.

Appendicceal diverticula may be associated with colonic diverticulosis or occur like a local phenomenon, being unique or multiple, and occurring along the entire length of the organ ${ }^{(1)}$. Congenital (or true) diverticula are exceedingly rare (less than 50 cases have been reported $)^{(2)}$. Acquired pseudodiverticula, characterized by herniation of the mucosa and submucosa through a defect in the muscular layer, have a reported incidence ranging from 0.04 to $2.8 \%{ }^{(1,3)}$.

Although diverticulosis of the appendix can present symptoms, as recurrent episodes of vague spontaneously resolving lower right abdominal quadrant pain ${ }^{(4)}$, most cases will not present symptoms until acute inflammation occurs (diverticulitis), typically associated to a fecalith impactation.

Diverticula create a structural change on the appendix and increase the possibility of infection. Up to two-thirds of the patients with diverticula will develop diverticulitis, occurring as an isolated process, or associated with secondary appendicitis. Some authors estimate that up to $2 \%$ of clinical appendicitis are in fact appendiceal diverticulitis with secondary periappendicitis ${ }^{(5)}$. Some cases will develop complications as perforation and abscess ${ }^{(6)}$.

Most patients will present atypical forms of appendicitis: the patient is over 30 years old, the abdominal pain is milder, the clinical course is longer and there is a history of previous attacks ${ }^{(7,8)}$. The patient does not seek medical care often until the symptoms become more pronounced, increasing the risk of perforation. It is important to note that acquired diverticula have a thin wall, which contributes to perforation. Actually, the incidence of perforation in appendiceal diverticulitis is four times greater than in usual appendicitis ${ }^{(8)}$.

The appendiceal diverticulitis is rarely identified preoperatively by imaging. Some case reports showed that double-contrast barium enema can demonstrate diverticulosis ${ }^{(3,8,9)}$, but not diverticulitis. The computed tomography may overlook the diverticula because of their small size. On the other hand, the literature suggest that diagnosis can be achieved by ultrasound, especially due to its higher spatial resolution ${ }^{(6,10)}$.

The ultrasound findings during graded compression include a focal or diffusely thickened appendiceal wall (> $3 \mathrm{~mm}$ ), and a non-compressible rigid dilated organ. The diverticula usually appear aswell-defined hypoechoic round or oval-shaped nodular lesions abutting the muscular layer of the appendix, usually near the tip. The diverticulum neck may be identified at the level of the vascular hiatus under optimal conditions ${ }^{(6)}$. An adjacent inflammatory reaction may appear as echogenic "ground glass" fat stranding 
and a thickened cecum or terminal ileum. Perforation is common, and may be characterized by discontinuity of the diverticulum wall and fluid collection. In the complicated advanced cases the diverticulum and even the appendix may no longer be visible.

The suggested management of appendiceal diverticulitis is early appendectomy whenever possible. Complicated cases may need more aggressive approach as in our case. Incidentally discovered diverticula have a controversial approach: some authors recommend elective appendectomy ${ }^{(9)}$, but this has not been widely accepted.

\section{CONCLUSION}

Appendiceal diverticulitis is an uncommon condition, probably underestimated and commonly overlooked. Clinical picture varies, frequently manifested as atypical appendicitis forms, with a greater risk of perforation than isolated appendicitis. Preoperative imaging diagnosis is possible by ultrasonography. Early surgical intervention is the preferred management to prevent complications.

\section{REFERENCES}

1. Esparza AR, Pan CM. Diverticulosis of the appendix. Surgery. 1970;67(6):922-8.

2. Phillips BJ, Perry CW. Appendiceal diverticulitis. Mayo Clin Proc. 1999;74(9):890-2.

3. Lawler LJ, Jackson R. Diverticulosis of the appendix: a case report. Australas Radiol. 1994;38(3):227.

4. Majeski J. Diverticulum of the vermiform appendix is associated with chronic abdominal pain. Am J Surg. 2003;186(2):129-31.

5. Bianchi A, Heredia A, Hidalgo LA, García-Cuyàs F, Soler MT, del Bas M, et al. Diverticular disease of the cecal appendix. Cir Esp. 2005;77(2):96-8

6. Barc RM, Rousset J, Maignien B, Lu M, Prime-Guitton CH, Garcia JF. [Diverticula of the appendix and their complications: value of sonography (review of 21 cases)]. J Radiol. 2005;86(3):299-309.

7. Palmer G, Seidal T, Weibull H. Perforated diverticulum of the appendix. Eur $J$ Surg. 1992;158(9):507-8.

8. Beswick JS, Desai S. Diverticular disease of the vermiform appendix and its clinical relevance. Australas Radiol. 1994;38(4):260-1.

9. Triadacilopoulos G. Image of the month. Appendiceal and sigmoid diverticulosis. Gastroenterology. 1997;113(4):1062, 1424

10. Macheiner $P$, Hollerweger A, Gritzmann N. Sonographic features of diverticulitis and diverticulosis of the vermiform appendix. J Clin Ultrasound. 2002;30(7):456-7. 